\title{
Contributions of intramyocardial sinusoids in pulmonary atresia and intact ventricular septum to a right-sided circular shunt
}

\author{
Robert M. Freedom and Donald P. Harrington \\ From the Department of Pediatrics, Division of Pediatric Cardiology (RMF), and Department of Radiology, \\ Cardiovascular Division, The fohns Hopkins University and Hospital, Baltimore, Maryland, U.S.A.
}

In the patient with congenital heart disease, the phenomenon termed 'circular shunt' implies that some of the right-to-left shunted blood returns to its chamber of origin through intracardiac channels or communications, hence bypassing the systemic capillary bed. We are reporting the angiographic appearance of a right-sided 'circular shunt' in 2 patients with pulmonary atresia, diminutive, hypertensive right ventricle, and intact ventricular septum. In these patients the intramyocardial sinusoids and diverticula form the anatomical basis for the right-sided 'circular shunt': blind, hypertensive right ventricle $\rightarrow$ intramyocardial sinusoids $\rightarrow$ coronary artery $\rightarrow$ coronary venous system $\rightarrow$ coronary sinus $\rightarrow$ right atrium $\rightarrow$ right ventricle. It is suggested that retrograde flow through these intramyocardial sinusoids may impede or limit normal diastolic coronary artery perfusion and may predispose to myocardial ischaemia and dysfunction. In addition, the natural history of these intramyocardial sinusoids and diverticula is discussed.

The concept of a 'circular shunt' in the patient with congenital heart disease was previously introduced by Shone and associates (1962). In the typical rightto-left intracardiac shunt, the blood participating in the shunt passes through the systemic capillary bed before it returns to its chamber of origin. In the phenomenon termed 'circular shunt', however, some of the shunted blood returns to its chamber of origin through intracardiac channels or communications, hence bypassing the systemic capillary bed.

There have been 3 adequately documented cases of 'circular shunt' (though undoubtedly there are more that are unreported). In 2 (Jue, Noren, and Edwards, I966), pulmonary atresia with a left ventricular-right atrial communication formed the anatomical basis for the circular shunt. In the other case (Shone et al., 1962), right atrial blood was shunted into the left atrium. Some of this blood was further shunted through a small ventricular septal defect into the right ventricle. Then in the presence of tricuspid regurgitation and severe pulmonary stenosis, some of the blood which had originated in the right atrium returned to that chamber to complete the circular shunt.

In two recently studied patients with pulmonary

Received 8 April 1974. atresia, diminutive right ventricle, and intact ventricular septum, a right-sided 'circular shunt' was demonstrated angiographically. The role of intramyocardial sinusoids as the basis for the circular shunt in these patients is the subject of this report.

\section{Patients}

Both patients presented in the first two days of life with cardiac cyanosis and profound hypoxaemia. Clinical examinations, chest radiographs, and electrovectorcardiograms were typical of pulmonary atresia, hypoplastic right ventricle, and intact ventricular septum (Gamboa, Gersony, and Nadas, 1966; Gersony et al., I967). Both patients underwent cardiac catheterization and angiography. Their haemodynamic data are summarized in the Table. Subsequent to this study, both were palliated by a systemic to pulmonary artery anastomosis.

\section{Angiographic findings}

Case I has undergone three cardiac catheterizations. A selective right ventricular angiocardiogram (not suitable for reproduction) performed at 2 days of age demonstrated pulmonary atresia, a hypoplastic, poorly contractile right ventricle, significant tricuspid stenosis, and intramyocardial sinusoids which either terminated blindly within 


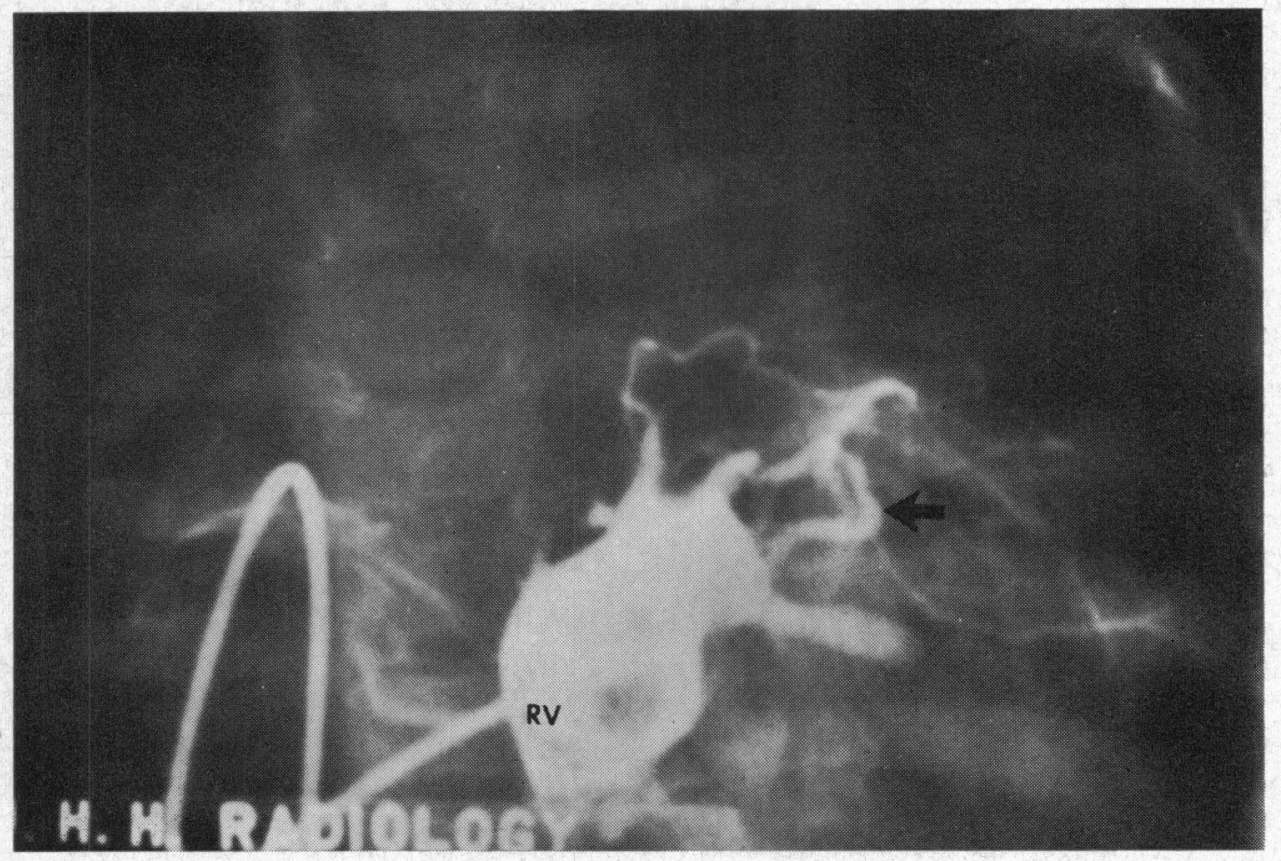

FIG. I Case I, age 22 months. A right ventricular angiocardiogram in the anteroposterior projection demonstrates a small, eccentrically shaped right ventricular chamber $(R V)$. An extensive network of myocardial sinusoids (arrow) communicates with the right ventricle. Opacification of the pulmonary artery is not seen.

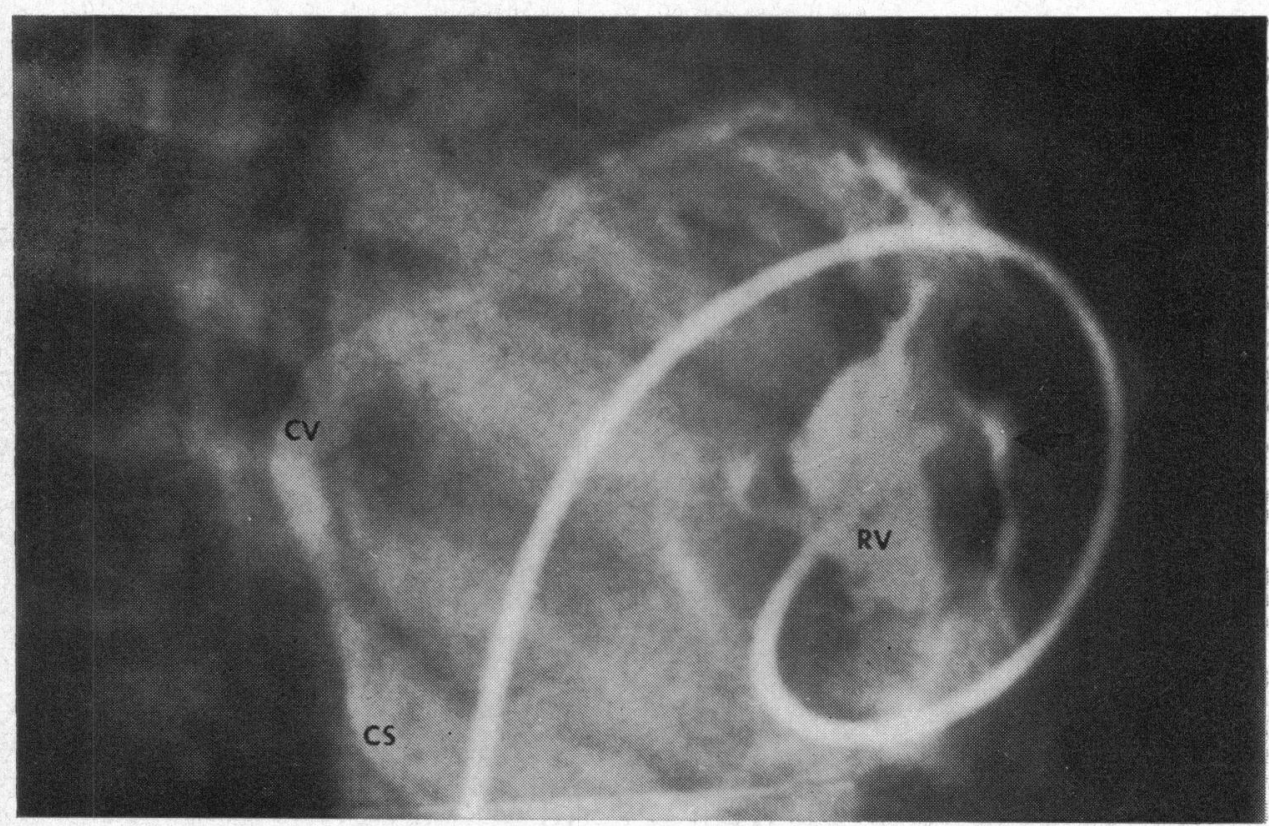

FIG. 2 Case 1 , age 22 months. A right ventricular angiocardiogram in the lateral projection (same study as Fig. I, later film). The right-sided circular shunt is well seen. The coronary vein $(C V)$ and coronary sinus (CS) are in direct continuity with the myocardial sinusoids and small right ventricle. No opacification of the coronary ostia or aortic root is appreciated in this sequence. 


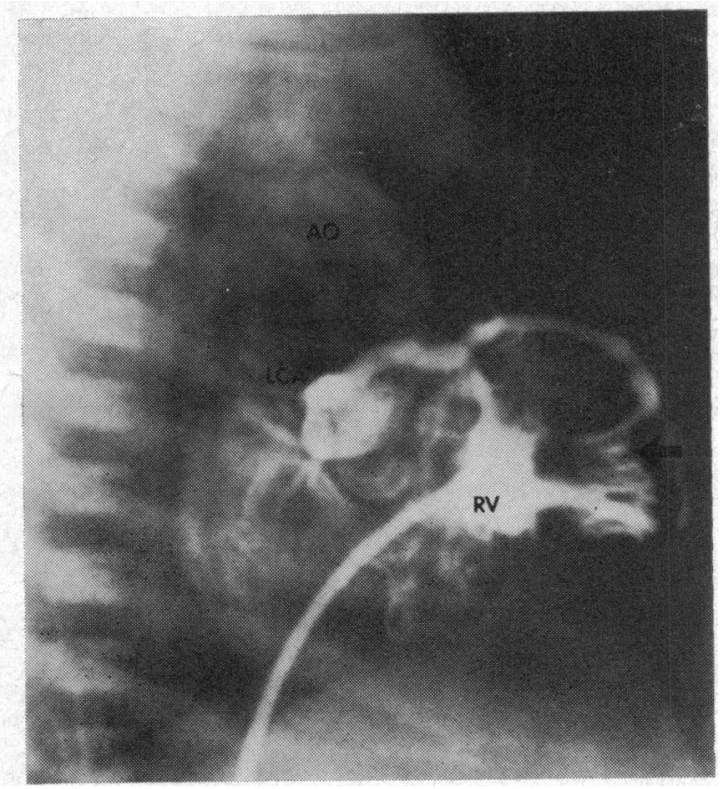

FIG. 3 Case 2, age 8 hours. Right ventricular angiocardiogram in the lateral projection. The diminutive right ventricle $(R V)$ and myocardial sinusoids (arrow) are well visualized. There is prompt opacification of the apparent anterior descending and left coronary artery $(L C A)$ and aortic root $(A O)$.

the myocardium or communicated with the anterior descending coronary artery. Opacification of the coronary sinus was noted. The patient was recatheterized at 6 months and at 22 months of age. The selective right ventricular angiocardiogram at 22 months of age demonstrated similar anatomical features (Fig. I). However, using only $\mathrm{I} \cdot \mathrm{O} \mathrm{ml}$ of Hypaque 75, slow hand injection into the right ventricle led to rapid opacification of intramyocardial sinusoids, coronary artery, coronary vein, and coronary sinus before visualization of the aortic root (Fig. 2). Indicator dilution curves performed by injection of green dye into the right ventricle with sampling in the coronary sinus and the ascending aorta yielded similar appearance times.

Case 2 was catheterized at 8 hours of age and again at 5 months. Selective right ventricular angiograms were performed at both studies. As in Case I, pulmonary atresia, a diminutive right ventricle, and minimal incompetence of the tricuspid valve were seen. In addition an extensive network of intramyocardial diverticula and sinusoids are present which communicate with the left coronary artery and densely opacify the left coronary ostia and aortic root (Fig. 3). Faint opacification of coronary sinus is noted.

\section{Discussion}

Since Grant first recognized intramyocardial sinusoid-coronary artery communications at necropsy (Grant, 1926), many reports relating to the embryology, anatomy, and angiographic findings have accumulated (Anselmi et al., I96I; Baker, Vogel, and Blount, 1967; Celermajer et al., 1968; Davignon et al., I96ra, b; Elliott, Adams, and Edwards, 1963; Guidici and Becu, 1960; Lauer et al., 1964; Williams, Kent, and Edwards, I95I).

In the patient with pulmonary atresia and intact ventricular septum, egress of blood from the blind right ventricle may take two possible courses. I) During right ventricular systole, blood may regurgitate through an incompetent tricuspid valve back into the right atrium and hence into the left atrium, left ventricle, and the systemic circulation, or 2) blood may be pumped during right ventricular systole from the hypertensive right ventricular cavity into the intramyocardial sinusoids (Sissman and Abrams, 1965). Histopathological and angiographic studies of these intramyocardial sinusoids

TABLE Catherization data

\begin{tabular}{|c|c|c|c|c|c|c|c|c|}
\hline & & \multicolumn{5}{|c|}{ Pressure data $(\mathrm{mmHg})$} & \multicolumn{2}{|c|}{ Oxygen saturation $(\%)$} \\
\hline & & $R A$ & $L A$ & $R V$ & $L V$ & Ao & $R A$ & Ao \\
\hline \multirow{3}{*}{ Case I } & $2 \mathrm{dy}$ & $\begin{aligned} a & =13 \\
m & =6\end{aligned}$ & $\begin{aligned} a & =12 \\
m & =6\end{aligned}$ & $60 / 10$ & $59 / 4$ & $54 / 45$ & 28 & 45 \\
\hline & & $\begin{aligned} a & =12 \\
m & =7\end{aligned}$ & $\begin{array}{r}a=6 \\
m=4\end{array}$ & $182 /$ I I & $89 / 7$ & $87 / 54$ & $5 \mathrm{I}$ & 78 \\
\hline & & $\begin{array}{l}a=18 \\
(10)\end{array}$ & $\begin{aligned} a & =\mathrm{II} \\
\mathrm{m} & =6\end{aligned}$ & $150 / 13$ & $98 / 10$ & I $15 / 70$ & 48 & 64 \\
\hline \multirow[t]{2}{*}{ Case 2} & $\begin{array}{l}8 \mathrm{hr} \\
5 \mathrm{mth}\end{array}$ & $\begin{aligned} a & =5 \\
m & =2 \\
a & =20\end{aligned}$ & $\begin{aligned} \mathrm{m} & =2 \\
\mathrm{a} & =\mathrm{I} 2\end{aligned}$ & $150 / 10$ & $60 / 6$ & $65 / 37$ & 47 & 55 \\
\hline & & $\mathrm{m}=8 \cdot 5$ & $\mathrm{~m}=7$ & $150 / 17$ & $85 / 7$ & $85 / 45$ & 45 & 87 \\
\hline
\end{tabular}




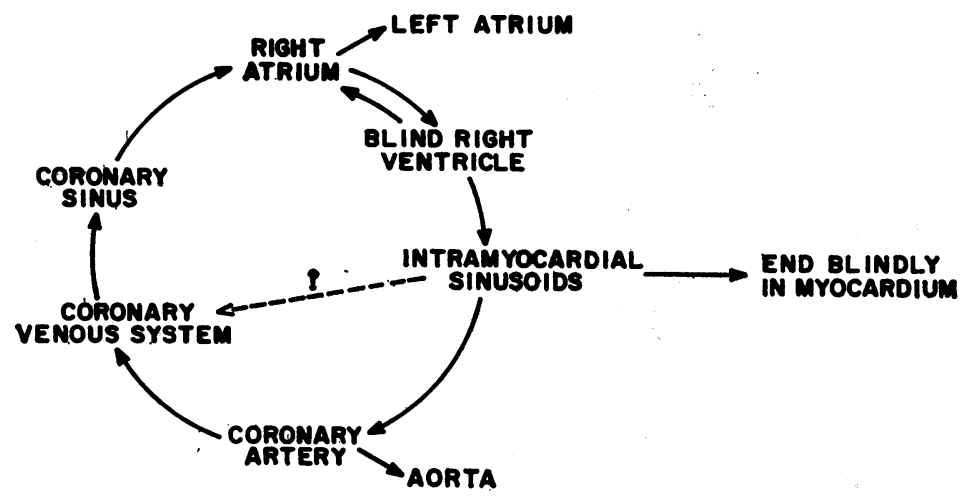

FIG. 4 Schematic portrayal of the right-sided circular shunt in the patient with pulmonary atresia, diminutive and hypertensive right ventricle, and intact ventricular septum. The intramyocardial sinusoids are the anatomical basis for this circular shunt.

suggest that they may either end blindly within the myocardium (Lauer et al., 1964) or may communicate with the coronary arteries (Elliott et al., 1963). It is not surprising, then, that injection of contrast material into the blind right ventricle could lead to immediate opacification of the coronary ostium and aortic root.

In the present cases, the intramyocardial sinusoids obviously communicate with the coronary arterial tree. Contrast material densely opacified sequentially the sinusoids, coronary artery, coronary venous system, and coronary sinus as well as the coronary ostium and aortic root. Thus, the intramyocardial sinusoids form the basis for this rightsided circular shunt in pulmonary atresia with intact ventricular septum (Fig. 4).

The observation that dense opacification of the coronary venous system occurs quite early is suggestive of direct communication between the intramyocardial sinusoids and the coronary venous system, though this has not been substantiated.

Though these sinusoids act as a passive conduit for the egress of blood from the blind right ventricle in the patient with pulmonary atresia and relatively competent tricuspid valve, do they by virtue of their communication with the coronary arteries contribute to myocardial ischaemia ? Numerous reports have documented the communication of these sinusoids with the anterior descending coronary artery (Cornell, 1966; Davignon et al., I96Ib; Elliott et al., 1963; Guidici and Becu, 1960; Lauer et al., 1964). As right ventricular systole will be prolonged in the patient with pulmonary atresia and intact ventricular septum, it is conceivable that normal aortic diastolic filling of the coronary arteries will be impaired by retrograde filling of the coronary arteries via the sinusoids, thus predisposing to ischaemic changes and myocardial dysfunction. It is of interest that left ventricular strain patterns have been recognized in the electrocardiograms of patients with pulmonary atresia and intact ventricular septum, before the performance of a systemic to pulmonary anastomosis (Celermajer et al., 1968; Elliott et al., 1963; Gamboa et al., 1966; Schrire, Sutin, and Barnard, I96I). In our patient (Case I), in the absence of significant left ventricular diastolic overload, the ejection fraction both by ultrasound and by angiography was less than 0.40 , consistent with significant left ventricular dysfunction. While it has been previously documented that left ventricular subendocardial muscle must receive all or most of its flow during diastole because intramyocardial compressive forces are highest in this area and hence prevent systolic perfusion of this muscle layer (Vincent, Buckberg, and Hoffman, 1974; Buckberg et al., 1972), it is possible that the left ventricular ischaemia and dysfunction might be related to the intramyocardial-sinusoids-coronary artery communications in the patient with severe right ventricular hypertension.

The natural history of the intramyocardial sinusoids in the patient with pulmonary atresia, hypertensive right ventricle, and intact ventricular septum is largely undefined. Regression of intramyocardial sinusoids has been observed in those patients in whom satisfactory decompression of the hypertensive right ventricle has been achieved by pulmonary valvotomy and infundibulectomy. In some patients studied serially in our institution the angiographic appearance may appear the same, or significant changes may be observed. In at least one patient a single large communication between 
intramyocardial sinusoid and coronary artery was identified at 2 days of age. Repeat study using similar angiographic technique at 5 months of age failed to demonstrate this intramyocardial sinusoidcoronary artery communication. There are two possible explanations for this observation. In situ thrombosis may have led to obliteration of the intramyocardial sinusoid and its communications. This seems unlikely because thrombosis in these channels has not been noted previously in published reports or in our own experience. It is more likely that secondary endocardial sclerosis may have occluded the endocardial orifice to the intramyocardial sinusoid. This seems more tenable because secondary endocardial sclerosis is well documented in these patients (Elliott et al., I963).

Although intramyocardial sinusoids are not unique to the patient with pulmonary atresia and intact ventricular septum, they are found most commonly in this group. Grant has previously suggested (Grant, 1926) that the intramyocardial sinusoids and diverticula represent abnormal persistence and ectasia of the intratrabecular spaces and their primitive communications with the coronary artery system, and their persistence is related to the severe fetal right ventricular hypertension.

Intramyocardial sinusoidal-coronary artery communications can occur with other significant anatomical variations in the coronary arteries. Recently, a most unique case was reported (Lenox and Briner, 1972). They described the clinical and necropsy findings of a 2-month-old infant with absent proximal coronary arteries, pulmonary atresia, intact ventricular septum, hypoplastic right ventricle, and Ebstein-like anomaly of the tricuspid valve. The coronary arteries in this patient were not connected to either the aorta or pulmonary artery, but originated from the intramyocardial sinusoids.

In summary, the intramyocardial sinusoids and diverticula are basic to a right-sided circular shunt in the patient with pulmonary atresia, hypoplastic and hypertensive right ventricle, and intact ventricular septum. They serve as a passive conduit for the egress of blood from the blind right ventricle, and may hinder normal diastolic coronary artery perfusion and hence predispose to ischaemic myocardial dysfunction.

\section{References}

Anselmi, G., Muñoz, S., Blanco, P., Carbonnell, L., and Puigbó, J. J. (I96I). Anomalous coronary artery connecting with the right ventricle associated with pulmonary stenosis and atrial septal defect. American Heart fournal, 62, 406.

Baker, W. P., Vogel, J. H. K., and Blount, S. G., Jr. (1967). Coronary artery - right ventricular communication associated with pulmonary atresia and ventricular septal defect. Circulation, 35, 923.
Buckberg, G. D., Fixler, D. E., Archie, J. P., and Hoffman, J. I. E. (1972). Experimental subendocardial ischemia in dogs with normal coronary arteries. Circulation Research, 30, 67.

Celermajer, J. M., Bowdler, J. D., Gengos, D. C., Cohen, D. H., and Stuckey, D. S. (1968). Pulmonary valve fusion with intact ventricular septum. American Heart fournal, 76, 452 .

Cornell, S. H. (1966). Myocardial sinusoids in pulmonary valvular atresia. Radiology, 86, 421.

Davignon, A. L., DuShane, J. W., Kincaid, O. W., and Swan, H. J. C. (I96ra). Pulmonary atresia with intact ventricular septum. Report of two cases studied by selective angiocardiography and right heart catheterization. American Heart fournal, 62, 690.

Davignon, A. L., Greenwold, W. E., DuShane, J. W., and Edwards, J. E. (I96rb). Congenital pulmonary atresia with intact ventricular septum. Clinicopathologic correlation of two anatomic types. American Heart fournal, 62, 591 .

Elliott, L. P., Adams, P., Jr., and Edwards, J. E. (I963). Pulmonary atresia with intact ventricular septum. British Heart Fournal, 25, 489.

Gamboa, R., Gersony, W. M., and Nadas, A. S. (1966). The electrocardiogram in tricuspid atresia and pulmonary atresia with intact ventricular septum. Circulation, 34, 24.

Gersony, W. M., Bernhard, W. F., Nadas, A. S.; and Gross, R. E. (1967). Diagnosis and surgical treatment of infants with critical pulmonary outflow obstruction. Study of thirty-four infants with pulmonary stenosis or atresia, and intact ventricular septum. Circulation, 35, 765 .

Grant, R. T. (1926). Unusual anomaly of coronary vessels in malformed heart of child. Heart, 13, 273.

Guidici, C., and Becu, L. (1960). Cardio-aortic fistula through anomalous coronary arteries. British Heart fournal, 22, 729.

Jue, K. L., Noren, G., and Edwards, J. E. (1966). Pulmonary atresia with left ventricular-right atrial communication: basis for 'circular shunt'. Thorax, 21, 83.

Lauer, R. M., Fink, H. P., Petry, E. L., Dunn, M. I., and Diehl, A. M. (1964). Angiographic demonstration of intramyocardial sinusoids in pulmonary-valve atresia with intact ventricular septum and hypoplastic right ventricle. New England fournal of Medicine, 271, 68.

Lenox, C. C., and Briner, J. (1972). Absent proximal coronary arteries associated with pulmonic atresia. American fournal of Cardiology, 30, 666.

Schrire, V., Sutin, G. J., and Barnard, C. N. (196I). Organic and functional pulmonary atresia with intact ventricular septum. American fournal of Cardiology, 8, 100.

Sissman, N. J., and Abrams, H. L. (1965). Bidirectional shunting in a coronary artery - right ventricular fistula associated with pulmonary atresia and an intact ventricular septum. Circulation, 32, 582.

Shone, J. D., Anderson, R. C., Elliott, L. P., Amplatz, K., Lillehei, C. W., and Edwards, J. E. (I962). Clinical pathological conference. American Heart fournal, 64, 547.

Vincent, W. R., Buckberg, G. D., and Hoffman, J. I. E. (1974). Left ventricular subendocardial ischemia in severe valvar and supravalvar aortic stenosis. A common mechanism. Circulation, 49, 326.

Williams, R. R., Kent, G. B., Jr., and Edwards, J. E. (195I). Anomalous cardiac blood vessel communicating with the right ventricle. Observations in a case of pulmonary atresia with an intact ventricular septum. Archives of Pathology, 52, 480.

Requests for reprints to Dr. Robert M. Freedom, Hospital for Sick Children, 555 University Avenue, Toronto, Ontario, Canada M5G IX8. 